Portland State University

PDXScholar

Summer 2021

\title{
The Relationship Between Regulation and Care Access in the Doula Industry
}

Charissa Billings

Portland State University

Follow this and additional works at: https://pdxscholar.library.pdx.edu/honorstheses

Part of the Health Policy Commons, Maternal and Child Health Commons, and the Women's Health Commons

Let us know how access to this document benefits you.

\section{Recommended Citation}

Billings, Charissa, "The Relationship Between Regulation and Care Access in the Doula Industry" (2021). University Honors Theses. Paper 1125.

https://doi.org/10.15760/honors.1156

This Thesis is brought to you for free and open access. It has been accepted for inclusion in University Honors Theses by an authorized administrator of PDXScholar. Please contact us if we can make this document more accessible: pdxscholar@pdx.edu. 
The Relationship Between Regulation and Care Access in the Doula Industry

\section{By: Charissa Billings}

An undergraduate honors thesis submitted for partial fulfillment of the requirements for the degree of

Bachelors of Science

in

University Honors

and

Public Health: Community Promotion

Thesis Advisor:

Dixie Whetsell, MS, IBCLC

Portland State University

2021 


\section{Background:}

\section{The Emergence of Birth Doula professionals}

For centuries, women have been helping women give birth. There is evidence of this in ancient artifacts and sculptures displaying the relationships between laboring mothers and their labor companions. Traditionally doulas were family members, neighbors, friends, or even a trusted community midwife who oversaw many of the births in the area. Today, a birth doula is defined commonly as a person trained to provide informational, emotional, and physical support and comfort to the birthing person before, during, and after childbirth (DONA, 2021). Birth doulas are trained to understand and know the birth process, various physical comfort measures, and ways to ease and help manage their client's emotions. Continuous labor support is defined and used differently throughout the literature. For the purposes of this review, I will be referring to continuous labor support as that provided by a doula.

Prior to the 20th century, birthing was done at home and with minimal interventions. The 2oth century had a boom in rapidly changing technologies and medicines to decrease infant and maternal deaths. By around the 1930s, only about $15 \%$ of births were attended by midwives, and the majority of families switched to hospital births attended by obstetricians (HealthLaw, 2020). The birthing process was now considered a medical procedure and many freedoms and controls were taken from the birthing person. During this time, women often labored without family support. Obstetricians also required that women labored and delivered lying on their backs to make the use of birthing tools or other interventions easier for them (Dunn. P, 1991). New and more frequent interventions were introduced that saved lives, but oftentimes interventions were used unnecessarily. Due to the advancement in medical technologies, the hospital was now seen as the safest place to give birth.

It is estimated that around the 1960 s and 1970 s the modern-day doula profession emerged, accompanied by the feminist movement. Around this same time, midwives began to work on reforming and reclaiming the birth space and giving the control back to the birthing 
person. There had been a shift of control from the birthing person to the physician in the medical setting. This movement was to try to shift birth from being seen as a medical procedure, back to being a natural occurrence of the body. It wasn't until 1992 that DONA International (then Doulas of North America) was created, which is a well-known organization that trains and certifies doulas all across the US and beyond (Healthlaw, 2020).

The United States has the highest maternal mortality rate amongst the most developed nations (Tikkanen et al., 2020). Our statistics are nearly double that of other industrialized nations. Racial disparities are even more staggering with the maternal mortality rate for non-Hispanic Black women being more than twice as high as White women (NCHS, 2020). This matter is urgent and deserves to be addressed in legislation. This literature review will lay out a solution that is cost-effective, contributes to employment, and most importantly improves birth outcomes.

\section{Evidence-Based Benefits of Doula Services}

Evidence shows that continuous support in labor improves birth outcomes, and that is no surprise. However, who provides that support and what they can bring to the experience is also significant. A nurse or midwife has expertise in childbirth, however, they have other worries and other things to focus on than comfort measures and emotional support for the birthing person during the whole duration of the labor. The partner or other family members have their own processes as well in connection with the birthing person or the whole experience and may not be able to be there for the person fully. The partner may be focused on this new life change, or having difficulty with watching their partner in pain or feeling out of control. A professional labor support person is there to fill in all those gaps and ultimately to be there fully for the laboring person, continuously. This could also mean consoling the partner or teaching them how to better support their partner. The type of continuous support and the quality of what support is needed is important. 
Many positive outcomes are enhanced by the presence of a doula even if other support people are present. For example, the decreased rate of cesarean birth is $25 \%$ with continuous support by a partner or family and friends, however, when that continuous support is provided by a doula the decreased rate of cesarean birth is $39 \%$. The rate of spontaneous birth is $8 \%$ but with that continuous support being from a doula it increases to $15 \%$ (Dekkar, 2019). A widely regarded Cochrane Review affirms that continuous labor support decreases labor duration, decreases pain medication use, decreases the use of epidurals, decreases cesarean births, decreases the use of synthetic oxytocin also known as Pitocin, babies are less likely to have a low APGAR score and laboring persons are more likely to have a satisfying experience overall (Bohren et al, 2017). The American College of Obstetricians and Gynecologists released this statement in 2017 and reaffirmed it in 2021, "evidence suggests that, in addition to regular nursing care, continuous one-to-one emotional support provided by support personnel, such as a doula, is associated with improved outcomes for women in labor (ACOG, 2017).”

\section{Certification}

Today, in the U.S, doulas are unregulated service providers. In order to practice as a doula, you do not need a license, certification, or proof of training. You can wake up one day, and decide to be a doula just as women have done for centuries past. However, clients in today's world, typically seek doulas with credentials of some kind. There are online training programs like BEST doula training or International Doula Institute's doula training. Or there are in-person workshop trainings like those with DONA International and Birthing From Within. Training content varies, as does recommended scope of practice. Certification can be expensive, especially if you are going through a subjectively thorough and credible institution. But even noncredible institutions charge a good amount of money. The information may be good and helpful, but only training or certifications from certain organizations can get you certain jobs, like as a hospital-employed doula or a Medicaid-covered doula. This is up to the employer or facility hiring you. Some training programs require hands-on training workshops, while others 
are more like an online education course. There are courses that get you certified right away, after viewing content and successfully completing an exam; While others require more experience and require you to purchase your certification packet after training.

Figure 1. Examples of a variety of certifying organizations or training.

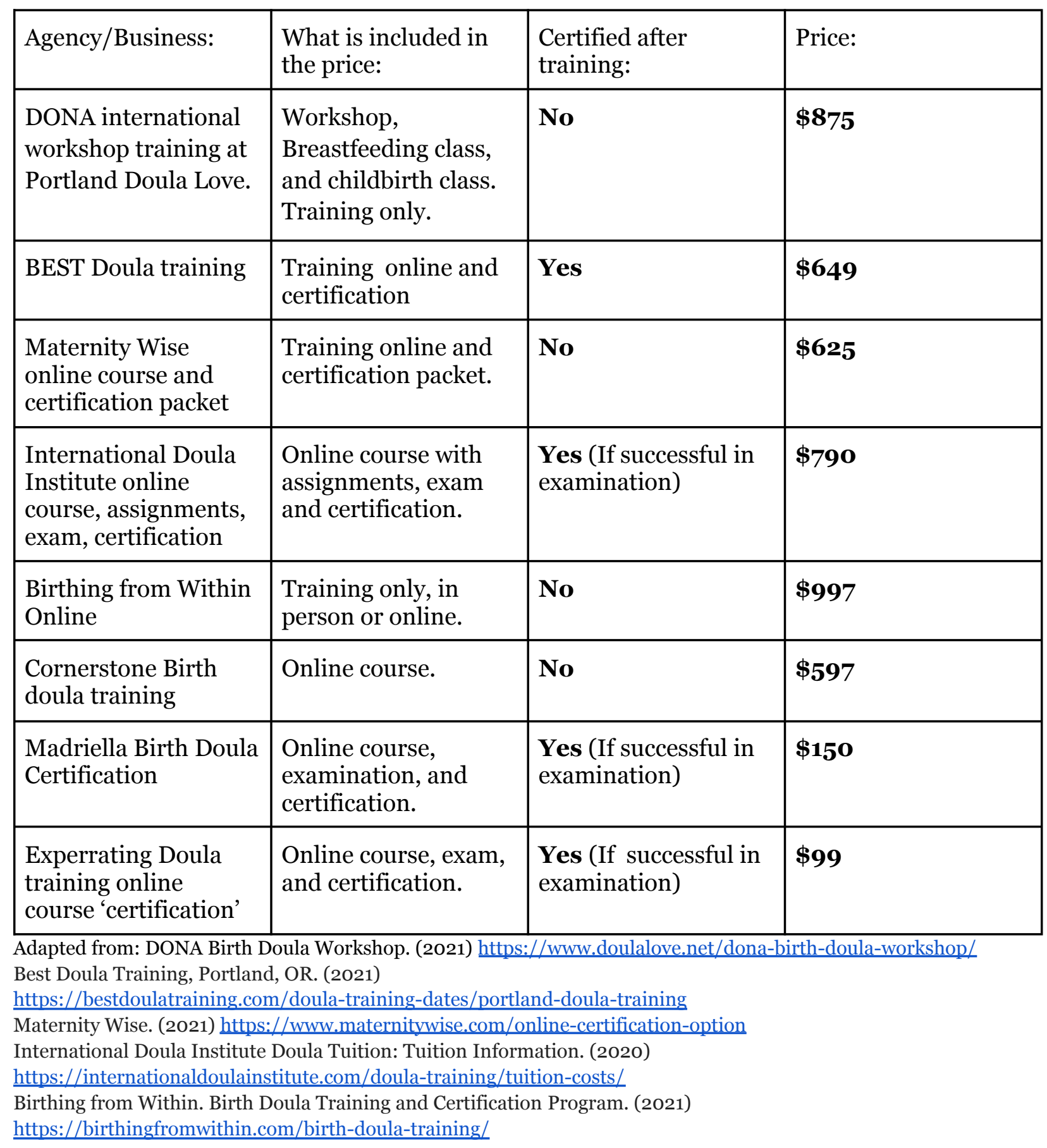


Cornerstone Doula Training. (2021) https://www.cornerstonedoulatrainings.com/courses

Madriella Membership Levels. (2019) https://madriella.org/enrollnow/

ExpertRating Doula Certification. (2021)

https://www.expertrating.com/certifications/Doula-Certification/Doula-Certification.asp?gclid=CjwKCAjwtpGGBhB JEiwAvRZX2h1nvcoeHoRoGF4dbAjoTllpwptiziGghb5GigFzp2V1rkah-lNdKhoCF-EQAvD BwE

\section{Regulation:}

The ongoing problem and controversy is to what extent should birth doulas and other birth workers have to be regulated to practice. Regulation is necessary for maintaining professionalism and credibility (Leslie et al, 2021). The regulation provides safeguards for both patients and providers. But the regulation also builds barriers for both patients and providers. Birth happens in a variety of settings, and doulas can also work in a variety of settings. And as mentioned before, you can practice as a doula without certification. Depending on the setting and whether the provider takes insurance, there are different regulatory measures. The regulation includes scope of practice, which will require that providers stay within their professional boundaries. Regulation of the doula industry gives clients peace of mind that their doula is trained, professional, and is a safe person to have in their birth space. They are inviting a stranger into a very important part of their lives, and the hope is that by the time the baby arrives, there is a trusting relationship built. Regulation often also drives prices up. Not every family that needs or wants a doula can pay certified private doula prices, so they may seek someone who doesn't have as much training or professionalism. Though in some states, there are volunteer-type programs that allow low-income families to have certified or trained doulas for a low price or even free of charge.

Without any financial coverage for doula services, many families wouldn't be able to afford it. Depending on location, prices vary from $\$ 800-\$ 2,500$ out of pocket (Weiss, 2021). This compensation for their time and availability to be on call allows for birth doula's to make a livable income. In order to ensure that they do not overbook, they can only take a few clients at a time. Many birth workers, whether they provide postpartum services or birth services, usually do it for supplemental income, which is a privilege in itself. As you search for information on 
doulas working full-time or how they manage their lives around their doula work, many articles and doula blogs appear. The vast majority of them discuss the management of both their doula job and their other jobs. Having to work both to sustain themselves is common, and also a barrier for most people. Juggling jobs, and needing a steady income are reasons many people decide not to pursue doula work. There are doulas who are able to work full-time and are excellent. But that is simply not the norm. Doulas who are full-time may have to charge higher rates to sustain themselves financially and there are not as many clients willing and able to pay as much out of pocket. The cost of doula services and the lack of insurance coverage limits who can benefit from the care doulas provide, therefore magnifying racial disparities as pointed out in this health blog about doula care, "racial disparities in severe maternal morbidity are linked to both clinical care practices and social determinants of health, doula care is a promising intervention to address two key drivers of maternal health inequities" (Health Affairs Blog, 2021). The implementation of Medicaid coverage with a sustainable reimbursement rate will allow doulas access to more clients who need or want them.

Access to doula care must also be balanced with the right for doulas to make a livable wage. If a certified and trained doula greatly improves birth outcomes and satisfaction during birth, while being on call at any given time, then they should be paid appropriately for that work. Kozhimannil's article Modeling the Cost-Effectiveness of Doula Care Associated with Reductions in Preterm Birth and Cesarean Delivery states, "Cost-effectiveness analyses indicate potential savings associated with doula support reimbursed at an average of $\$ 986 ”(2016)$. This rate is reasonable for the support, hours, and flexibility of schedule. Since a cesarean birth costs twice as much as a vaginal birth and babies born before 37 weeks gestation cost approximately 10 times more than a full-term baby, doula services that lower the rates of preterm deliveries and cesarean births would be cost-effective for insurance (Kozhimannil,2016).

The provision of both private and Medicaid reimbursed doula services expands the access to more people in search of services. Regulation, in turn, improves the quality of care and 
in this case of expanding Medicaid coverage also increases access to doula care. However, regulations may also restrict the services that doulas can offer. Some doulas may not be willing to work within a more regulated practice. Regulation may impose a strict scope of practice for doulas. This will require training that may improve the quality of care, however, it may also exclude some doula services like the provision of herbal remedies, or placenta encapsulation. Under the regulation, those services wouldn't be covered and would not allow them to be provided.

\section{Medicaid and Current Legislation:}

At this time, over 75 million people are on Medicaid in the United States (Matej Mikulic, 2020). And according to MACPAC (Medicaid and CHIP Payment and Access Commission), "Medicaid paid for 43 percent of all births in 2018, while private coverage paid for just under half (49.1 percent). Fewer births were uninsured (4.1 percent) or paid by another payer (3.8 percent)." This means that Medicaid provides insurance coverage for a large number of people who would qualify for doula services and could benefit from the support emotionally and physically.

As of June 2021, there have been 32 acts presented in the United States relating to doula services and Medicaid coverage. This is absolutely an ongoing conversation with many layers of regulation at play, from certifying organizations, to coverage, to recognizing doulas as medical service providers (Healthlaw, 2021). There have only been 5 passed bills total in history related to doula coverage by Medicaid and they were by individual states. Federally, there have not been any bills passed, but a few have been introduced in 2019 and 2020. Due to the threat to Medicaid coverage under the Trump administration, many acts were to keep many low-income mothers under coverage, not to necessarily expand coverage benefits and funding. MOMMIES act, Healthy MOMMIES act, Mama’s first act, Maternal CARE act, and Rural Maternal and Obstetric Modernization of Services Act all include doulas in their act descriptions in 2019. As it stands in spring of 2021, 5 states have doula services covered by Medicaid, Oregon, Minnesota, 
Indiana, New Jersey, and most recently in June 2021, Rhode Island (State of Rhode Island, 2021)(Healthlaw, 2019). New York also has doula services covered in a pilot program.

Oregon and Minnesota have it set up as an optional benefit under Medicaid. The following information about our current insurance coverage of birth doula services was retrieved from National Academy for State Health Policy (NASHP) unless otherwise indicated. In order for this benefit to be established there had to be provider qualifications, a list of covered services, reimbursement rates determined, ways to bill Medicaid, and contracts for doulas to be part of the health plan. In order to qualify for Medicaid payment in Minnesota, you must complete doula training through one of the Minnesota-approved organizations, which are the bigger names in the doula industry. Then you must enroll in the Minnesota Department of health doula registry which will cost you \$200. And finally, you must work under the supervision of a Medicaid physician or midwife. In Oregon, you first must complete certification requirements which include a certain number of hours of training and births attended. Then you must register as a traditional health worker which is free. The final steps include obtaining a National Provider Identifier (NPI) then enrolling as a Medicaid provider, so you can bill your services.

Medicaid reimbursement rates differ between these two states. Minnesota covers sessions that include the birth, each session doulas receive $\$ 47$ and then $\$ 488$ for the birth, which can be any number of hours long. They must be billed by the supervising physician, which has proven to be difficult due to many variables. In Oregon, most doulas get paid the "global payment" which includes at least 4 visits, 2 prenatal visits, and 2 postpartum visits, and then the day of delivery, which is all $\$ 350$. There is also an option for those not providing the entire package, which means $\$ 50$ per visit (up to 4 ) and $\$ 150$ for the day of delivery. For Oregon doulas, they bill OHA directly, or through an organization that does it for them. Services must also be at the request of an obstetric provider. 
Indiana uses a Title V MCH block grant to cover doula services (NASHP, 2020). This is to support the state's efforts in reducing maternal and infant mortality rates for black families. This coverage is at risk of reduction or cancellation due to grant money running dry or change in management grantee organization.

New Jersey is one of the recent states to add doula services under Medicaid. They require doulas to obtain approved training, to obtain a National Provider Identifier (NPI), to have individual liability insurance, and then apply to be a "fee for service" provider for their state's Medicaid. New Jersey has two levels of doula care. The more enhanced care is for those patients 19 and younger, who qualify for 12 visits plus attendance of delivery. The standard care for patients older than 19 qualify for 8 visits and attendance of the delivery. The reimbursement looks promising with prices per prenatal/postpartum visit at about $\$ 66$ and $\$ 235$ for the attendance of delivery (NJ Department of Human Services, 2021).

And lastly, Rhode Island is the most recent state to pass a bill to include doula care under Medicaid (State of Rhode Island General Assembly, 2021). There is not much information out yet about the process, but care is set to be covered in July 2022.

\section{Policy Recommendation:}

Due to the expanding evidence that birth doulas help improve both infant and maternal birth outcomes, my policy recommendation is to expand Medicaid coverage to include birth doula services in the United States and to create a living reimbursement rate for doula providers. Private doulas should also be able to continue to practice within hospital institutions. This policy recommendation will provide access to those who need their birth services covered, will give Medicaid-covered birth doulas a fair and livable wage, and will allow those who are seeking private doulas or are a private birth doula, to continue practicing. 


\section{References:}

ACOG Committee Opinion No. 766: Approaches to Limit Intervention During Labor and Birth. (2019). Obstetrics \& Gynecology, 133(2). doi:10.1097/aog.0000000000003074

Approaches to Limit Intervention During Labor and Birth. (n.d.). Retrieved from https://www.acog.org/clinical/clinical-guidance/committee-opinion/articles/2019/02/ap proaches-to-limit-intervention-during-labor-and-birth

Asteir Bey et al., ( 2019, March 25). Advancing Birth Justice: Community-Based Doula Models as a Standard of Care for Ending Racial Disparities https://everymothercounts.org/wp-content/uploads/2019/03/Advancing-Birth-Justice-C $\underline{\text { BD-Models-as-Std-of-Care-3-25-19.pdf }}$

Best Doula. Portland, Oregon Doula Training. (n.d.). Retrieved from https://bestdoulatraining.com/doula-training-dates/portland-doula-training

Birth Doula Training and Certification Program. (2021, March 06). Retrieved from https://birthingfromwithin.com/birth-doula-training/

Bohren, M. A., Hofmeyr, G. J., Sakala, C., Fukuzawa, R. K., \& Cuthbert, A. (2017). Continuous support for women during childbirth. The Cochrane database of systematic reviews, 7(7), CDoo3766. https://doi.org/10.1002/14651858.CDo03766.pub6

Cara B. Safon Lois McCloskey Caroline Ezekwesili Yevgeniy Feyman Sarah H. Gordon. (2021, May 26). Doula Care Saves Lives, Improves Equity, And Empowers Mothers. State Medicaid Programs Should Pay For It: Health Affairs Blog. Retrieved from https://www.healthaffairs.org/do/10.1377/hblog20210525.295915/full/

Chen, A., \& Robles-Fradet, A. (2020, May 21). Building A Successful Program for Medi-Cal Coverage For Doula Care: Findings From A Survey of Doulas in California. Retrieved from https://healthlaw.org/resource/doulareport/

Chen, A. (2019, May 06). Routes to Success for Medicaid Coverage of Doula Care. Retrieved from 
https://healthlaw.org/resource/routes-to-success-for-medicaid-coverage-of-doula-care

Chen, A. (2021, May 29). Doula Medicaid Project. Retrieved from

https://healthlaw.org/doulamedicaidproject/

Cornerstone Courses. (n.d) Retrieved from

https://www.cornerstonedoulatrainings.com/courses

Dekkar, R. RN PhD, Evidence on: Doulas. (2019, August 12). Retrieved from

https://evidencebasedbirth.com/the-evidence-for-doulas/

DONA. What is a Doula. (2018, December 05). Retrieved from

https://www.dona.org/what-is-a-doula/

DONA Birth Doula Workshop. (n.d.). Retrieved from

https://www.doulalove.net/dona-birth-doula-workshop/

Doula. (n.d.). Retrieved from https://www.merriam-webster.com/dictionary/doula

Doula Tuition: Tuition Information. (2020, July 09). Retrieved from

https://internationaldoulainstitute.com/doula-training/tuition-costs/

Dunn P. M. (1991). "Childbirth: lessons from the past". West of England medical journal, 106(4), 98. https://www.ncbi.nlm.nih.gov/pmc/articles/PMC5115091/

Ellmann, N. (n.d.). Community-Based Doulas and Midwives. Retrieved from https://www.americanprogress.org/issues/women/reports/2020/04/14/483114/commu nity-based-doulas-midwives/

Everson, C., Crane, C., \& Nolan, R. Advancing Health Equity for Childbearing Families in Oregon: Results of a Statewide Doula Workforce Needs Assessment. 2018 Oregon Doula Association Estacada, OR. Retrieved from https://www.oregon.gov/oha/OEI/Documents/Doula\%20Workforce\%20Needs\%20Asse sment\%20Full\%20Report\%202018.pdf

ExpertRating. (n.d.). Retrieved from https://www.expertrating.com/certifications/Doula-Certification/Doula-Certification.asp 
?gclid=CjwKCAjwtpGGBhBJEiwAyRZX2h1nvcoeHoRoGF4dbAjoTllpwptjziGghb5GigFzp 2V1rkah-lNdKhoCF-EQAvD BwE

Four State Strategies to Employ Doulas to Improve Maternal Health and Birth Outcomes in Medicaid. ' (2020, July 6th). Retrieved from

https://www.nashp.org/four-state-strategies-to-employ-doulas-to-improve-maternal-hea $\underline{\text { lth-and-birth-outcomes-in-medicaid/ }}$

Gebel, B. C. (2020, January 09). Expanding Access to Doula Care: State of the Union. Retrieved from https://www.mhtf.org/2020/01/o8/expanding-access-to-doula-care/

Hardeman, R. R., \& Kozhimannil, K. B. (2016). Motivations for Entering the Doula Profession: Perspectives From Women of Color. Journal of midwifery \& women's health, 61(6), 773-780. https://doi.org/10.1111/imwh.12497

Hodnett, E. D., Gates, S., Hofmeyr, G. J., \& Sakala, C. (2013). Continuous support for women during childbirth. The Cochrane database of systematic reviews, 7, CDoo3766. https://doi.org/10.1002/14651858.CDo03766.pub5

How Has Childbirth Changed in This Century? (n.d.). Retrieved from https://www.takingcharge.csh.umn.edu/explore-healing-practices/holistic-pregnancy-chi $\underline{\text { ldbirth/how-has-childbirth-changed-century\# }}$

Kozhimannil, K. B., Attanasio, L. B., Jou, J., Joarnt, L. K., Johnson, P. J., \& Gjerdingen, D. K. (2014). Potential benefits of increased access to doula support during childbirth. The American journal of managed care, 20(8), e340-e352.

Kozhimannil, K. B., Hardeman, R. R., Alarid-Escudero, F., Vogelsang, C. A., Blauer-Peterson, C., \& Howell, E. A. (2016). Modeling the Cost-Effectiveness of Doula Care Associated with Reductions in Preterm Birth and Cesarean Delivery. Birth (Berkeley, Calif.), 43(1), $20-27$. https://doi.org/10.1111/birt.12218 
Kozhimannil, K. B., Hardeman, R. R., Attanasio, L. B., Blauer-Peterson, C., \& O’Brien, M. (2013). Doula Care, Birth Outcomes, and Costs Among Medicaid Beneficiaries. American Journal of Public Health, 103(4). doi:10.2105/ajph.2012.301201

Kozhimannil, K. B., Vogelsang, C. A., Hardeman, R. R., \& Prasad, S. (2016). Disrupting the Pathways of Social Determinants of Health: Doula Support during Pregnancy and Childbirth. Journal of the American Board of Family Medicine : JABFM, 29(3), 308-317. https://doi.org/10.3122/jabfm.2016.03.150300

Leslie, K., Moore, J., Robertson, C., Bilton, D., Hirschkorn, K., Langelier, M. H., \& Bourgeault, I. L. (2021). Regulating health professional scopes of practice: Comparing institutional arrangements and approaches in the US, Canada, Australia and the UK. Human Resources for Health, 19(1). doi:10.1186/s12960-020-00550-3

Madriella Network. Select your Membership Level (2019, October 29). Retrieved from https://madriella.org/enrollnow/

Maternity Wise. Online Doula Courses. (n.d.). Retrieved from https://www.maternitywise.com/online-certification-option

NVSS - Maternal Mortality - Homepage. (2020, November 09). Retrieved from https://www.cdc.gov/nchs/maternal-mortality/

Obstetric Care Consensus No. 1. (2014). Safe prevention of the primary cesarean delivery. Obstetrics \& Gynecology,123(3), 693-711. doi:10.1097/01.aog.0000444441.04

Pando, D. (2020, October 26). New: HC One Issue Brief: Creating Policy for Equitable Doula Access. Retrieved from https://www.healthconnectone.org/new-hc-one-issue-brief-creating-policy-for-equitabledoula-access/

Robin Elise Weiss, P. (2021, June 14). How Much Does a Doula Cost? Retrieved from https://www.verywellfamily.com/how-much-does-a-doula-cost-4123633 
Roosa Tikkanen et al., Maternal Mortality and Maternity Care in the United States Compared to 10 Other Developed Countries (Commonwealth Fund, Nov. 2020). https://doi.org/10.26099/411v-9255

State of New Jersey Department of Human Services Division of Medical Assistance \& Health Services (February, 2021). Medicaid/NJ FamilyCare Coverage of Doula Services ${ }^{* *}$ Revised Billing Codes ${ }^{* *}$ Retrieved from https://www.state.nj.us/humanservices/dmahs/info/Newsletter 31-04 Doula.pdf State of Rhode Island General Assembly. (2021). Retrieved from http://www.rilin.state.ri.us/pressrelease/ layouts/RIL.PressRelease.ListStructure/For

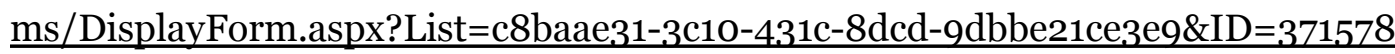

State Policy Approaches to Incorporating Doula Services into Maternal Care. (n.d.). Retrieved from https://www.astho.org/StatePublicHealth/State-Policy-Approaches-to-Incorporating-Do ula-Services-into-Maternal-Care/08-09-18/

Strauss, N., Sakala, C., \& Corry, M. P. (2016). Overdue: Medicaid and Private Insurance Coverage of Doula Care to Strengthen Maternal and Infant Health. The Journal of Perinatal Education, 25(3), 145-149. doi:10.1891/1058-1243.25·3.145

Thomas, M., Ammann, G., Brazier, E., Noyes, P., \& Maybank, A. (2017). Doula Services Within a Healthy Start Program: Increasing Access for an Underserved Population. Maternal and Child Health Journal, 21(S1), 59-64. doi:10.1007/s10995-017-2402-0

Tikkanen. R, Gunja. M, FitzGerald. M \& Zephyrin. L (18, November 2020) Maternal Mortality and Maternity Care in the United States Compared to 10 Other Developed Countries. (n.d.). Retrieved from https://doi.org/10.26099/411v-9255

Villarosa, L. (2018, April 11). Why America's Black Mothers and Babies Are in a Life-or-Death Crisis. Retrieved from 
https://www.nytimes.com/2018/04/11/magazine/black-mothers-babies-death-maternal -mortality.html 